\title{
Research on the Inheritance of Ceramic Industry civilization in Jingdezhen Post-industrial Landscape Design
}

\author{
Cui Dong ${ }^{1, a}$ \\ ${ }^{1}$ School of Art and Design, Jingdezhen Ceramic Institute, Jingdezhen, China \\ a aminy530@163.com
}

Keywords: Post-industrial landscape, Industry civilization, Inheritance, Jingdezhen

\begin{abstract}
The formation of Jingdezhen industry civilization has a closed relationship with the development of ceramic industry after the founding of the nation, the industry civilization of which has experienced the process from developing, thriving and wearing off. It has left lots of ceramic industry sites. The inheritance principle and method of ceramic industry civilization in Jingdezhen post-industrial landscape design are proposed through analyzing the significance of industry civilization inheritance, characteristics and conservation status of Jingdezhen ceramic industry sites.
\end{abstract}

\section{Introduction}

The industry civilization in Jingdezhen has created the glory of Jingdezhen ceramic industry and has brought immeasurable effects on the city and economic development in Jingdezhen. Nowadays, along with the abandoning of industrial sites, the industry civilization of Jingdezhen fades away during the city high-speed development process. To inherit and protect the achievements of industry civilization in Jingdezhen is an important topic to promote Jingdezhen urban transformation.

\section{Significance of Inheriting Industry Civilization}

Industry civilization is a significant symbol of modern civilization, and its main characteristics include industrialization, urbanization and mechanization, etc., which are not only characteristics of industry civilization, but also a determinant of transformation from agriculture civilization to industry civilization. As an important constituent part of human civilization, industry civilization promotes the development of human society in a relatively active and aggressive method, which has created profound influence on the history and today. It is also the method and mean of inheriting industrial class lofty spirit and industry civilization to keep true and relatively complete industrial age historical information, retain the specific carrier of industry civilization, put people in the history to feel the production and living conditions at that time, which will make people experience that common cultural memory at the most intuitively and cultivate strong social identity and sense of belonging. To keep each production section, going from factory area planning, building construction, and mechanical equipment, industrial procedures and final products, retain the achievements of industry civilization at each stage to concatenate into a complete development sequence will either leave a complete development track to later ages, or leave precious basis of the human being history development.

\section{Characteristics of Jingdezhen Ceramic Industry Sites}

Jingdezhen started to produce porcelains since the Five Dynasties with a long history of porcelain production, has made outstanding contributions for the great development of ceramic industry in our country and left lots of ceramic industry sites and resources. It still keeps ancient kiln sites, workshops, warehouses and other ceramic production process and equipment under each historical background to this day. The ceramic industry sites are the context continuation of the traditional ceramic industry with characteristics of large span, rich gross and concentrated distribution. The main existing ceramic industry heritages in Jingdezhen mainly include "red tower" 
of Jingdezhen Ceramic Institute old campus, Ceramic Research Institution of Ministry of Light Industry, especially dozens of locally-administered enterprises successively built after the founding of the nation, including Jianguo Porcelain Factory, Weimin Porcelain Factory, Guangming Porcelain Factory, Renmin Porcelain Factory, Hongqi Porcelain Factory, Yuzhou Porcelain Factory, Art Porcelain Factory, etc. We used to call them "ten top porcelain factories". Besides, there are some Jingdezhen historic kiln sites. At present, there are 52 historic kiln sites registered in the archaeological survey, and most of them are well preserved. The remains unearthed by archeologists involve the Five Dynasties, Song, Yuan, Ming and Qing Dynasty, which are typical material elements recording and reflecting the ceramic industry history development of Jingdezhen (Figure 1). These existing ceramic industry heritages are distributed in the urban area of Jingdezhen, relatively concentrated, with very high historical and cultural value, social value, economic value, scientific and technological value as well as aesthetic value, which not only become the testimony of history of contemporary ceramic industry development in Jingdezhen, but also are effective carriers of inheriting the traditional ceramic industry culture.

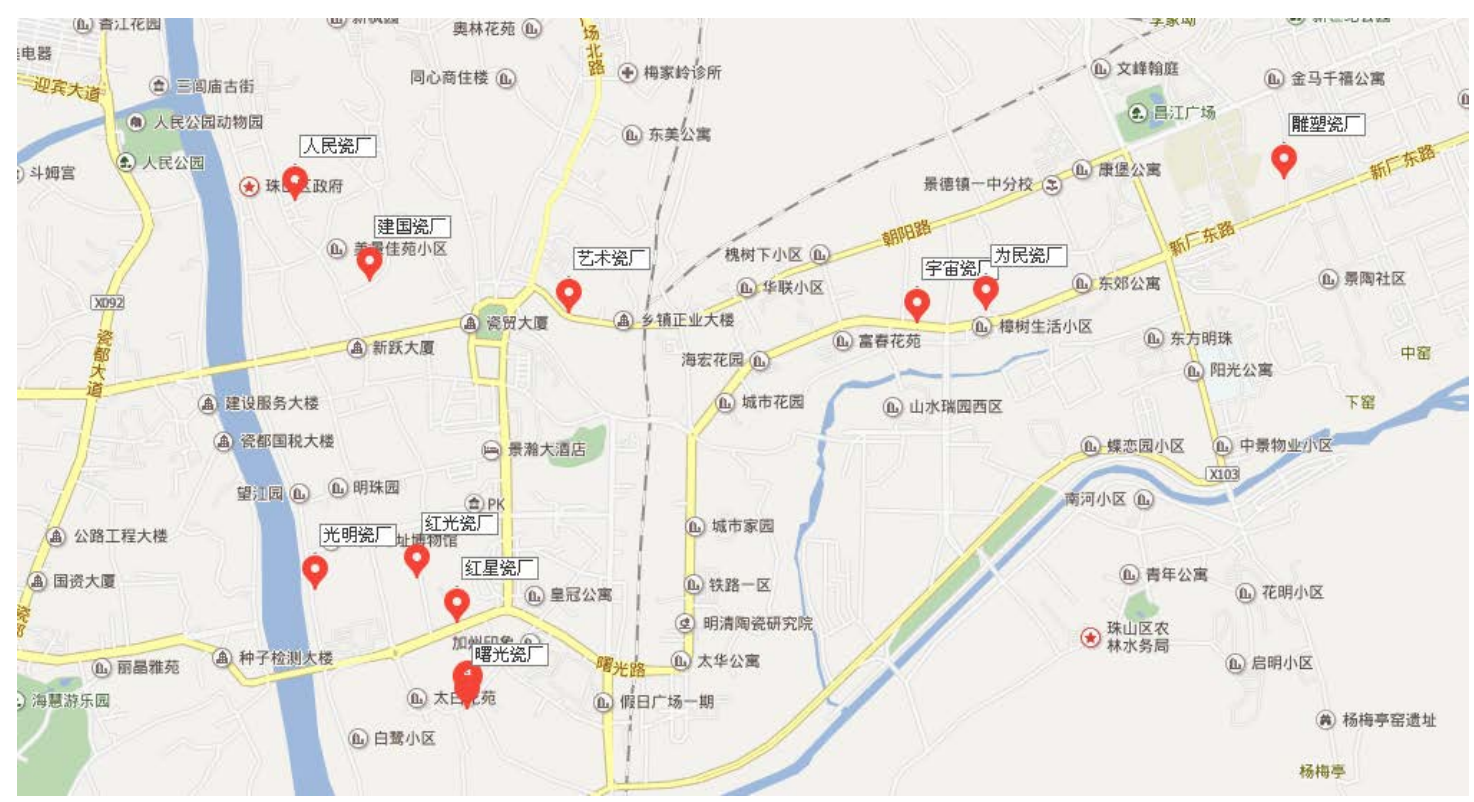

Figure 1 Distribution map of “top ten” ceramic factories in Jingdezhen

\section{Current Situation and Problems of Jingdezhen Ceramic Industry Heritage Protection}

Along with the adjustment of social industrial structure and the alteration of economic situation, the previous ceramic industry is left unused or transformed gradually during the process developing to modern machine manufacturing. Lots of ceramic industry sites are left in Jingdezhen. As prompted by the creative cultural industry, partial ceramic industry sites in Jingdezhen are protected and developed to some extent and form mature cultural creative towns. Those transformed successfully include Sculpture Porcelain Factory Cultural Creative Town, Jianguo Porcelain Cultural Creative Town and "Taoxichuan - China Workshop" Cultural Creative Town; but their transformation form is single, taking promoting urban tourism and economic growth as the purpose, neglecting the continuation of urban ceramic industry context, the integration of industrial site landscape and the connection of surrounding environment and restraining the sustainable development of urban environment. As shown in figure 2, weeds spring up in other ceramic industry sites without transformation, which go to rack and ruin; and many early industrial buildings become main operating places of some individual workshops. 

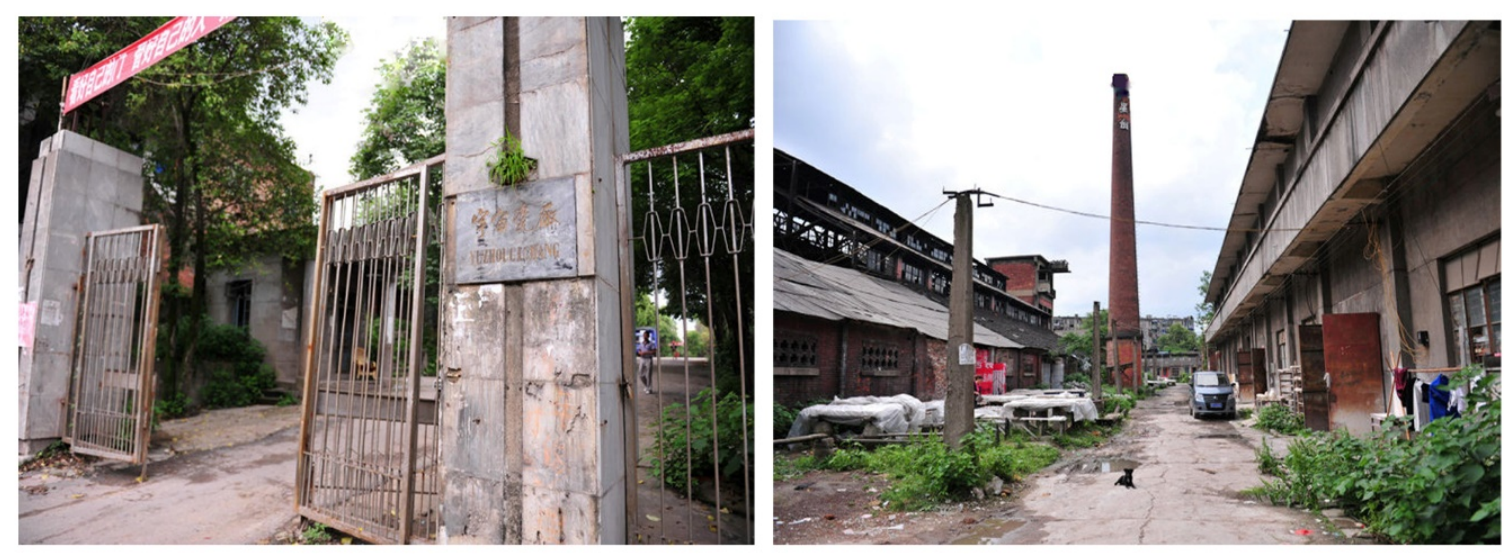

Figure 2 The present situation of Jingdezhen old porcelain factory.

\section{Inheritance Principle and Method of Ceramic Industry Civilization in Jingdezhen Post-industrial Landscape Design}

Post-industrial landscape "means to keep, transform, update and use various industrial facilities, surface traces, wastes and others on industrial sites and take them as main landscape elements to design and build." To inherit Jingdezhen ceramic industry civilization in the post-industrial landscape design method needs to follow certain principles and methods.

\subsection{Respect Regional Context Characteristics}

Regional characteristics are characteristics that one city is different from the other cities. The cultural sensitivity of cities is very high; regional cultural connotation elements are not only results of historical accumulation, but also significant origins displaying the post-industrial landscape character. Furthermore, they are of distinct characteristics and can give industrial sites appearances with full of tension. Jingdezhen depends on porcelain; there is no doubt that ceramic culture is the most typical regional culture of Jingdezhen. Buildings, structures, industrial equipment and others within industrial sites are identification of a region, which are also significant media that we feel history and recall history. When transforming and reusing them, we should follow the characteristics of regional context, take the ceramic element as the entry point, extract the language of post-industrial landscape design, transform and update reasonably on the industrial sites to continue the ceramic industry civilization.

\subsection{Seek Place Spirit}

Buildings, constructions, equipment and others in industrial sites constitutes the main body of industrial sites, the level of scattered wave, crossing vertically and horizontally, with incomparable characteristics, the spatial pattern of which constitutes the entire space intention of industrial sites as well. Therefore, in the post-industrial landscape design, we should respect and pay attention to space pattern characteristics of industrial sites and keep space characteristics of sites. When making them display the spirit of industrial sites, we should approach human dimensions and get people's identification of the site culture. Instead of just transforming buildings, rebuilding the floor and increasing vegetation, the post-industrial landscape design should increase infrastructures, give more leisure functions to industrial sites, increase the participatory of sites and make them be one part of the daily casual of surrounding residents. The cultural connotation will attract visitors better; thus, people can feel industrial cultural during the entertainment, and the purpose of teaching through lively activities will be reached.

\subsection{Build Ecological Space}

The ceramic industry is a resources consumption industry with very serious pollutions, especially the ceramic production section, which can produce wastewater, exhaust gas, smoke dust, heavy 
metal lead, etc. Although old porcelain factories have been halted, their influences on the soil $\mathrm{pH}$, vegetation and air around it still exist. The ecological renovation and management become the basis of the post-industrial landscape design. Therefore, to introduce the concept of ecological aesthetics in the post-industrial landscape design and apply ecological technology and high-tech technology to recover the original ecological environment is the first question to resolve to build ecospace. Besides, for some exhaust gases without pollution, they can be turned into wealth and reused. For some waste materials without pollution to the environment, for example, external tiles, potsherds and others of waste industrial buildings, we can process them slightly and take them as floor decoration, communal facilities, leisure chairs and featured landscape. On the one hand, it reduces the claim for new energy and new materials and complies with the principle of ecological design; on the other hand, it can build site characteristics in the landscape renovation and reach the effect of keeping historical information to the hilt.

\subsection{Form Linear Ceramic Industrial Heritance Landscape Corridor}

Heritance corridor is a major form of heritance areas, which means "linear landscapes with special cultural resource collection”. Industrial heritage is the sum of the tangible cultural heritage and intangible cultural heritage kept during the industrialization development process, which is a unity that several cultural elements interacts and associate with each other. Therefore, the principle of "integrated conservation" should be insisted when protecting industry cultural heritage. The integrated protection of Jingdezhen industrial culture not only needs to "remain old as before" on old buildings and old kiln sites of each industrial heritage, but also needs to concatenate each existing post-industrial sites in Jingdezhen, take the ceramic industry civilization as core, form linear ceramic industry heritage landscape corridor and series up ceramic industry heritage resources and other natural and recreation resources with the common historical theme along the line to realize comprehensive purposes of regional industry heritage protection, ecology and environment, leisure and education, social and economic development and others and undertake the significant responsibility of inheriting Jingdezhen ceramic industry civilization.

\section{Conclusion}

Industrial culture is built on the massive historic basis through the integration and heritage of post-industrial landscape, but it is built on the demands of the time on the future development, which not only displays the cultural spirit and regional characteristics, but also meets the demand of city development. Digging the aesthetic resources left in the ceramic industry heritage injects new materials and new blood in the landscape design field and widens the design view and method of the landscape design. Therefore, in the post-industrial landscape transformation in Jingdezhen ceramic industry sites, we should fully dig and inherit the ceramic industry civilization, respect the wasted industrial historical context, continue industrial civilization, protect and update industrial heritages reasonably.

\section{Acknowledgements}

This research was supported by the Humanities and Social Scientific Research Project in Universities of Jiangxi Province in 2016 (NO.YS162023).

\section{References}

[1] Jiadong Yu. (1997) History of Jiangxi Ceramics. Henan University Press.189-194.

[2] Binlin Yu. Study on the Development Overview of Jiangxi Ceramic Industry Company. Jingdezhen's Ceramics, 2003(1), 57-62.

[3] Qiong Zhu,Qibin Ai,Yidong Wang. Anoverview of the Jingdezhen Ceramics Industry Heritage. China Ancient City, 2013(5), 48-52. 
[4] Huiqiong Wang. The Cultural Heritage Research of Industrial Heritage Landscape Transformation. Xi'An University of Architecture and Technology(2015).

[5] Wein Gao. Industry Heritage Culture Landscape Conformity Based on Urban Card. Chinese \& Overseas Architecture. 2012,(2): 57-58.

[6] Jie Shen, Zefeng Xu. Analysis of the Urban Post-Industrial Landscape Design Reuse. Chinese \& Overseas Architecture. 2011,(11): 98-99. 